\title{
Aspectos legales: para nacionales y extranjeros
}

\author{
Legal aspects: for nationals and foreigners \\ José Salvador Aburto-Morales* \\ * Director General del Centro Nacional de Trasplantes de la Secretaría de Salud.
}

\section{GENERALIDADES}

Todo el proceso de trasplante se encuentra regulado por nuestro marco normativo expreso en Ley General de Salud, reglamento interior de la Secretaría de Salud y Reglamento de la Ley General de Salud en materia de trasplantes. ${ }^{1-3}$

Aspectos legales para donación en nacionales

\section{Donador vivo relacionado}

- Ser mayor de edad y estar en pleno uso de sus facultades mentales.

- Donar un órgano o parte de él que al ser extraído, su función pueda ser compensada por el organismo.

- Tener compatibilidad con el receptor.

- Recibir información completa sobre los riesgos de la operación y las consecuencias de la extracción.

- Haber otorgado su consentimiento de forma expresa.

\section{Donador vivo no relacionado}

- Obtener resolución favorable del comité de trasplantes de la institución hospitalaria, donde se vaya a realizar el trasplante, previa evaluación médica, clínica y psicológica.
- El interesado en donar deberá otorgar su consentimiento expreso ante notario público y en ejercicio del derecho que le concede la presente ley, manifestando que ha recibido información completa sobre el procedimiento por médicos autorizados, así como precisar que el consentimiento es altruista, libre, consciente y sin que medie remuneración alguna. El consentimiento del donante para los trasplantes entre vivos podrá ser revocable en cualquier momento previo al trasplante.

- Haber cumplido todos los requisitos legales y procedimientos, para comprobar que no se está lucrando con esta práctica.

Aspectos legales para donación en extranjeros

\section{Donador vivo relacionado*}

- Ser mayor de edad y estar en pleno uso de sus facultades mentales.

- Donar un órgano o parte de él, que al ser extraído su función pueda ser compensada por el organismo.

- Tener compatibilidad aceptable con el receptor.

- Recibir información completa sobre los riesgos de la operación y las consecuencias de la extracción.

* Relacionado: entre familiares por consanguinidad, civil o de afinidad hasta el cuarto grado. 
- Haber otorgado su consentimiento en forma expresa, en términos de los artículos 322 y 323 de la Ley General de Salud.

- Acreditar su legal estancia en el país con la calidad migratoria ${ }^{\ddagger}$ específica que corresponda.

- Se deberá agregar al expediente clínico original o copia certificada de la documentación que compruebe la relación de parentesco, debidamente apostillada o, en su caso, legalizada.

- El comité interno de trasplantes deberá levantar un acta firmada por todos sus integrantes, en la que se haga constar que no existen circunstancias que hagan presumir una simulación jurídica o comercio de órganos, tejidos y células, o bien, hechos de coacción hacia el donador.

- El establecimiento en el que se vaya a realizar el trasplante deberá inscribir al paciente al registro nacional de trasplantes con una antelación de al menos 15 días hábiles.

\section{Donador vivo no relacionado}

- Ser mayor de edad y estar en pleno uso de sus facultades mentales.

- Donar un órgano o parte de él que al ser extraído su función pueda ser compensada por el organismo.

- Tener compatibilidad aceptable con el receptor.

- Recibir información completa sobre los riesgos de la operación y las consecuencias de la extracción.

- Haber otorgado su consentimiento en forma expresa, en términos de los artículos 322 y 323 de la Ley General de Salud.

- Acreditar su legal estancia en el país con la calidad migratoria ${ }^{\ddagger}$ específica que corresponda.

- Una permanencia comprobable en territorio nacional de al menos seis meses ininterrumpidos (Art. 22 Reglamento materia trasplantes) previos a la realización del trasplante, salvo en casos de hepatitis fulminante debidamente documentada.

- El receptor deberá contar con un expediente clínico de al menos seis meses en el establecimiento de salud en el que vaya a realizarse dicho trasplante.

- El establecimiento en el que se vaya a realizar el trasplante deberá inscribir al paciente al Registro Nacional de Trasplantes con una antelación de al menos seis meses.

‡ Calidad migratoria: residente temporal, residente temporal estudiante 0 residente permanente.

\section{Donador fallecido}

- Comprobar, previamente a la extracción de los órganos y tejidos y por un médico distinto a los que intervendrán en el trasplante o en la extracción de los órganos o tejidos, la pérdida de la vida del donante.

- Existir consentimiento expreso del disponente, que conste por escrito o no constar la revocación.

- Proporcionar información completa, amplia, veraz y oportuna al o la cónyuge, el concubinario. la concubina, los descendientes, los ascendientes, los hermanos, el adoptado o el adoptante de la persona fallecida, de los procedimientos que se llevarán a cabo.

- Asegurarse que no exista riesgo sanitario.

- Cumplir con los aspectos legales y administrativos.

Puntos críticos a optimizar

Nacionales

- Donante vivo no relacionado: contar con acta del comité, evaluación de salud mental y comité de bioética, consentimiento ante notario público/jurídico de la institución.

- Trasplante en cadena-reporte al Sistema Informático del Registro Nacional de Trasplantes.

\section{Extranjeros}

- Conocer la normativa aplicable en donación/ trasplantes en extranjeros.

- Solicitar la consulta al Centro Nacional de Trasplantes del cumplimiento de la normativa aplicable en donación/trasplantes en extranjeros.

- Reporte al Sistema Informático del Registro Nacional de Trasplantes antes de la realización del trasplante.

- Reporte al Sistema Informático del Registro Nacional de Trasplantes posterior de la realización del trasplante, incluyendo seguimiento (supervivencia) a 1, 3, 5 y 10 años.

\section{RECOMENDACIONES}

1. Conocer la normatividad/procedimiento estandarizado del Subsistema Nacional de Donación y Trasplantes.

2. Informe oportuno a los pacientes y familiares sobre los procedimientos. 
3. El Centro Nacional de Trasplantes seguirá apoyando en la asesoría de donación/trasplantes en extranjeros.

\section{COMENTARIOS}

1. Legalmente no existe distinción entre pacientes pediátricos y adultos. El protocolo deberá determinar los criterios de prioridad en la asignación a los pacientes pediátricos.

2. La Ley no restringe donantes por criterios de edad, por lo que todos pueden ser valorados y médicamente considerados.

3. El Centro Nacional de Trasplantes no tiene la atribución de certificar programas.

4. El Centro Nacional de Trasplantes puede promover la creación de lineamientos para trasplante en cadena.

5. La documentación migratoria de personas extranjeras que requieren trasplante son un requisito necesario para la prevención de tráfico de órganos y turismo de trasplantes.

6. La regulación de la actividad y las autorizaciones sanitarias son competencia de COFEPRIS
(Comisión Federal para la Protección contra Riesgos Sanitarios).

7. En el caso de extranjeros, el establecimiento deberá asegurar el seguimiento, para lo cual será necesario establecer mecanismos efectivos de referencia-contrarreferencia.

8. El Centro Nacional de Trasplantes supervisa la actividad registrada en el Sistema Informático del Registro Nacional de Trasplantes de manera periódica, para lo cual colabora con los Centros y Consejos Estatales de Trasplantes.

\section{REFERENCIAS}

1. Secretaría de Salud. Ley General de Salud. Diario Oficial de la Federación, 14 de junio de 1992.

2. Secretaría de Salud. Reglamento Interior de la Secretaría de Salud. Diario Oficial de la Federación, 31 de enero de 2018.

3. Secretaría de Salud. Reglamento de la Ley General de Salud en materia de trasplante. Diario Oficial de la Federación. 26 de marzo de 2014.

Correspondencia:

Dr. José Salvador Aburto-Morales

E-mail: jose.aburto@salud.gob.mx 